\title{
Research on Innovation and Development of Construction Technology of Civil Engineering
}

\section{Fu Longlong, Zhou Lihong}

Nanchang Institute of Science and Technology, Nanchang, China

Keywords: civil engineering; construction technology; research on innovation and development

\begin{abstract}
With the continuous progress and development of China's society and economy, the construction industry embraces the unprecedented opportunity for development, with the increasing number of civil engineering constructions around the whole country. The quality of construction engineering is directly related to people's life safety, so relevant national departments pay attention to the construction quality of civil engineering and construction technology. Therefore, enterprises shall actively adapt to the changes of social and economic development trend, constantly conduct innovations, strengthen the studies on new technologies, comprehensively improve the construction quality and efficiency of engineering, and reduce the costs, so as to strive to occupy a position in fierce market competition, enhance their economic and social benefits and make contributions to national economic and social development.
\end{abstract}

In a narrow sense, civil engineering refers to infrastructure engineering constructed by construction enterprises for national economic construction, scientific research, production activities, people's daily life, diversified military activities and so on, including railway, dam, port, ocean platform, airport, protective engineering, water supply and sewerage works for municipal administration, etc. Whereas, in a broad sense, it refers to activities such as exploration, design, repair, post maintenance and so on implemented by various construction materials and mechanical equipment. It can be seen that the construction technology of civil engineering is closely related to national economic development and people's daily life. The new era puts forward higher requirements for the construction technology of civil engineering, therefore, enterprises shall actively carry out technological development and innovation to enhance the construction of civil engineering.

\section{The Development and Basic Points of Civil Engineering Construction Technology}

\subsection{The development of civil engineering construction technology}

The construction technology of civil engineering involves complex contents, including construction maintenance, preliminary design, construction mechanical equipment and construction materials and so on, to meet the basic demand from people for daily production and life and provide necessary material guarantee for people. Through long-term technological research and accumulated experience, the construction technology of civil engineering gradually develops and becomes mature. At present, relevant technologies have been applied in water conservancy project, railway project, bridge engineering and construction industry. After years, China's construction technology of civil engineering is continuously developing and carrying out innovations. For instance, the representative engineering such as the Water Cube and Bird's Nest have shown Chinese advanced construction technology of civil engineering. Nowadays, with the improving science and technology, people put forward higher requirements for the construction technology of civil engineering. Traditional technologies of steel structure, concrete structure and foundation cannot satisfy current social development. Therefore, enterprises are required to vigorously implement strategic transformation and upgrading, comprehensively improve the construction ability, keep up with the times, and constantly seek for breakthrough and development in the new era to make contributions to national progress. 


\subsection{The basic points of civil engineering construction technology}

The construction of civil engineering involves an extensive scope, and the construction technology plays a decisive role in the overall quality of engineering. In order to meet current people's requirements for the quality and functional performance of engineering, it is necessary to carry out technological innovations. At present, the construction technology mainly involves prestressed concrete structure, open caisson, cast-in-place concrete pile, foundation, wet shotcrete, excavation of foundation pit and so on. In terms of the prestressed concrete structure, due to the external force, the pressure is applied by human factors so that the whole structure is in prestressed state, avoiding the external load to generate tensile force on the concrete structure to affect the stability of the overall structure. The application of advanced prestressed technology can enhance the strength and tensile properties of the overall structure, and at the same time promote the overall improvement of the concrete maintenance and avoid the adverse effects of various cracks. The main structure of the open caisson is cylindrical, which belongs to the basic technology of filling the bottom in concrete construction, and it can effectively overcome the resistance generated by the friction of the well wall and ensure that the sinking can reach a more accurate height during the construction process. Concrete filling technology is relatively traditional. It is the basic technology for excavation by various mechanical equipment or manpower. With a wide application range, it can improve the concrete maintenance and reduce the adverse effects on the formation structure. The pore forming process includes dry construction pore forming, artificial borehole, explosion, casting pipe pore forming and so on. Foundation is an important technology affecting the construction quality of civil engineering, whose stability plays a decisive role in the overall quality of engineering. In order to avoid the serious sink of building structure, it is necessary to deeply study the foundation construction technology.

The excavation of foundation pit mainly includes the excavation technology of deep foundation pit and shallow foundation pit. In the excavation of deep foundation pit, it is necessary to rationally design the basic structure of the supporting baffle to avoid the safety accidents such as collapse and improve the structural stability of the soil wall [1]. In general, when selecting the supporting method, it is necessary to combine the actual conditions of the project construction. The structure with the retaining soil and water needs to adopt the chemical grouting filling and the underground diagram wall, the $\mathrm{H}$-shaped steel pile and double-row cast-in-place pile need the baffle, and the structure retaining soil and pervious to water requires the pre-placed pile structure. Shallow foundation pit supporting needs to inspect the construction area in detail in the early stage of construction operation, understand the specific soil layer structure, reasonably determine the specific excavation time and the technical means to be used to ensure that the construction technology is completely consistent with the specific soil structure of the construction. In actual operation, the groundwater level in the construction area is high, the soil moisture is suitable and relatively well-balanced, so it is necessary to strictly operate according to the relevant standards of Guojiabao during the construction process, reduce construction time and improve work efficiency [2].

\section{The Innovations on Construction Technology of Civil Engineering}

The application of civil engineering construction technology is extensive, and the effects of specific operation have a great influence on the construction quality of engineering. In the preliminary design, it is necessary for designers to inspect on site, combine with the actual conditions of the engineering, reasonably select construction materials and mechanical equipment, determine the construction method suitable for engineering, at the same time, take fully subjective factors such as weather and natural environment into consideration, set reasonably construction procedures, actively carry out technological innovations and comprehensively enhance the construction quality and efficiency [3]. 


\subsection{The innovations on presstressed construction technology}

The prestressed construction technology plays an important role in the construction of civil engineering. Traditional prestressed technology is mainly to place prestressed rebar inside the concrete structure. In constructing some building for special purpose and large-scale buildings, operation error is easy to occur for technicians, resulting the wrong position of rebar. The new-type prestressed technology belongs to prestressed technology outside the building, as an important component in back pull presstressed structure system of civil engineering. Different from traditional technology, it is in the outside the entire cross section of concrete, and it can realize the perfect integration of bonded prestressed and unbonded prestressed technology. The application of this technology in construction environment with higher accuracy can improve the post-maintenance. In the inspection, it is not necessary to dismantle building structure, which can reduce the investment in time and costs, suitable for the important development trend of construction industry. Currently, it is widely applied in long-span bridge engineering and road engineering [4].

\subsection{The innovations on deep foundation pit technology}

At present, deep foundation pit technology is mainly adopted in high-rise buildings, and it is an important technological means to guarantee the secure overall quality of high-rise buildings. In order to innovate the deep foundation pit technology, it is required to adopt pile cap structure movement for supporting to realize the overall increase of soil layer hardness. For high-rise buildings with relatively free soil, perfusion and prestressed anchor column reinforcement can be used to improve the overall strength of the soil structure. The concrete perfusion technology has a large bearing capacity and good adaptability, with a wide application range. The perfusion technology needs to be filled to a depth of more than $100 \mathrm{~m}$ and a caliber of not less than $3 \mathrm{~m}$ during the actual operation. During the construction process, the cement slurry is poured into the surrounding area of the construction area to achieve protection of compressive resistance of the overall structure. This technology can enhance the construction efficiency and save construction costs. In innovating the overall pile-shaped structure of the project, it is necessary to innovate the bottom pile and the pile-drived pile structure. The reasonable hammer vibration design can effectively avoid the deviation and the damage of the pile body.

\subsection{The innovations on deep foundation pit supporting}

The soil nailing wall technology needs to avoid soft soil foundation, and the diagram wall structure is suitable for deep foundation pit engineering with strict construction requirements. In the construction of high-rise buildings, the fully enclosed underground diagram wall structure is generally adopted. However, due to the excessive thickness of the wall, there is big difficulty in fixing. Therefore, in construction, the construction structure protection with convenient disassembly can be adopted, and the protection structure shall be implemented simultaneously with water retaining and earthwork construction. The innovative prestressed technology can also be adopted to comprehensively improve the strength of supporting structure of buildings, avoid the opposite acting force generated from the transformation of rebar structure and prevent the security accidents because of the transformation of supporting wall. Technicians can apply circular supporting structure in construction to bring convenience for earthwork excavation and undermining and soil shoveling, prevent the transformation of the overall structure and reduce the negative effects of space in construction area on engineering [5].

\subsection{The innovations on the fence technology of deep foundation pit}

At present, all sectors of the society put forward higher requirements for the overall quality of construction engineering. Therefore, technicians can vigorously carry out technological innovation, increase the stability of construction structure and ensure the security of construction structure. The innovations on the fence technology of deep foundation pit is an important content of innovations on construction technology of civil engineering, among which, anchorage and supporting system is the most representative technology. When the excavation depth of the civil engineering is deep, the 
technicians need to carry out a comprehensive survey of the geological conditions of the area. When the density of the pit wall is too low or the soil is free soil, the bolt perfusion technology can be used to comprehensively improve the quality and efficiency of the construction [6]. For different groundwater conditions, technicians should reasonably adopt casing water technology and innovative anchoring technology to comprehensively improve construction quality and efficiency of engineering construction. At the same time, for permanent supporting, temporary reinforcement piles, underground supporting structures, etc., technicians can adopt the supporting structure and load-bearing integration, give full play to the role of load-bearing structure, improve project stability, reduce consumption and cost, and increase the economic benefits and social benefits of enterprises.

\subsection{The improvement of management system and application of information technology}

The innovations on construction technology of civil engineering rely on advanced management system. It is necessary to set constraints on behaviors of technicians and ensure the scientificity and completeness of innovation system. In order to guarantee the results of technological innovations, related departments shall improve their management system, encourage technicians to study and research, formulate the sound reward system to provide necessary rewards for technicians with excellent abilities and engineering with excellent innovation results, so as to bring convenient conditions for the innovations of civil engineering. According to various problems in the practical application of traditional civil engineering technology, management staff shall conduct in-depth investigation, combine with actual conditions, abandon backward technologies with low effects and actively explore to apply new technologies, improve the construction efficiency and reduce costs, to create favorable conditions for the development of civil engineering by virtue of various new technologies [7]. Meanwhile, based on the extensive application of information Internet technology, new technologies such as Internet shall be actively applied in the innovations on civil engineering technology, and the education and training of personnel in civil engineering shall be strengthened so that they can proficiently grasp the working mode of Internet, and enhance their understanding of various knowledge. The combination of civil engineering technology and Internet can improve the working efficiency and innovative ability of enterprises.

\section{The Development Trend of Civil Engineering Technology in the Future}

The development of construction industry is closely related to the progress of science and technology. The automation will become the important development trend of construction industry in the future, and various automatic and integrative equipment will be widely applied in the practive of construction. Civil engineering technology innovation needs to actively change the production mode, transform the mode of manual production into a production mode of assembly line, and comprehensively improve construction efficiency. At the same time, science and technology is also an important development trend of civil engineering technology. Through the technological innovation of civil engineering technology, it can reduce the overall costs of civil engineering projects, reduce the expenditure of enterprises in machinery and equipment, labor costs, etc., and improve the economic and social benefits while guaranteeing the overall qualified quality of engineering. The application of advanced technical means can promote the intelligent development of civil engineering construction, truly transform advanced science and technology into productivity, and promote the overall improvement of work efficiency and social benefits [8]. In addition, China is vigorously emphasizing the sustainable development of the ecological environment at present, and the resource-saving society is the main development direction in the future. Civil engineering technology is essentially the adoption of natural resources to transform the living environment of human beings. In the future, in the process of technological innovation, it is necessary to pay attention to improving the comprehensive utilization rate of various building materials, vigorously carry out energy-saving and environmentally-friendly materials, reduce the use of contaminated building materials, and promote the effective combination of economic development and environmental protection. 


\section{Conclusion}

The civil engineering technology plays an irreplaceable role in the development of relevant industries. Therefore, relevant personnel shall strengthen the research, constantly conduct innovations, improve the construction quality and efficiency by virtue of new technologies and realize the comprehensive development of construction industry in the new era.

\section{References}

[1] Wang Qi. Exploration of Construction Technology of Civil Engineering and Innovation [A]. Construction Technology and Management Organizing Committee. The Symposium of Academic Seminar on Construction Technology and Management in September, 2018 [C]. Construction Technology and Management Organizing Committee: Beijing Hengshengboya International Cultural Communication Center, 2018: 2.

[2] Li Jing. Research on Construction Technology of Civil Engineering [A]. Construction Technology and Management Organizing Committee. The Symposium of Academic Seminar on Construction Technology and Management in April, 2018 [C]. Construction Technology and Management Organizing Committee: Beijing Hengshengboya International Cultural Communication Center, 2018: 2.

[3] Jiang Tao. Research on the Relationship between the Structure Design of Civil Engineering and Construction Technology [A]. Construction Technology and Management Organizing Committee. The Symposium of Academic Seminar on Construction Technology and Management in April, 2018 [C]. Construction Technology and Management Organizing Committee: Beijing Hengshengboya International Cultural Communication Center, 2018: 2.

[4] Liu Jianmin. Discussion on Concrete Construction Technology of Civil Engineering [A]. Construction Technology and Management Organizing Committee. The Symposium of Academic Seminar on Construction Technology and Management in April, 2018 [C]. Construction Technology and Management Organizing Committee: Beijing Hengshengboya International Cultural Communication Center, 2018: 2.

[5] Wang Shixiang. Analysis on Construction Technology of Civil Engineering [A]. Construction Technology and Management Organizing Committee. The Symposium of Academic Seminar on Construction Technology and Management in April, 2018 [C]. Construction Technology and Management Organizing Committee: Beijing Hengshengboya International Cultural Communication Center, 2018: 3.

[6] Xu Yongfeng. Empirical Study on Professional Evaluation of Civil Engineering [A]. The scientific results of Research on Teachers' Teaching Ability Development (Volume 14) [C]. The research group of Research on Teachers’ Teaching Ability Development, 2018: 4.

[7] Qi Hongying. Research on Concrete Construction Technology of Civil Engineering [A]. Construction Technology and Management Organizing Committee. The Symposium of Academic Seminar on Construction Technology and Management in December, 2017 [C]. Construction Technology and Management Organizing Committee: Beijing Hengshengboya International Cultural Communication Center, 2017: 3.

[8] Song Bingqing. Analysis on Concrete Structure Construction in Civil Engineering [A]. Construction Technology and Management Organizing Committee. The Symposium of Academic Seminar on Construction Technology and Management in July, 2017 [C]. Construction Technology and Management Organizing Committee: Beijing Hengshengboya International Cultural Communication Center, 2017: 1. 